\title{
Chemotherapy-induced nausea and vomiting (CINV) with carboplatin plus pemetrexed or carboplatin plus paclitaxel in patients with lung cancer: a propensity score-matched analysis
}

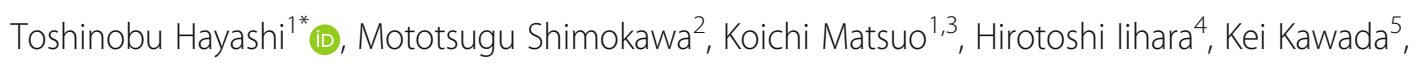
Takafumi Nakano ${ }^{1}$ and Takashi Egawa'

\begin{abstract}
Background: Patients with lung cancer who are treated with carboplatin-based chemotherapy regimens often experience chemotherapy-induced nausea and vomiting (CINV). However, knowledge on the effect of regimen and cofactors on the risk of CINV is limited. This study aimed to analyze and compare the incidence of CINV between lung cancer patients undergoing carboplatin plus pemetrexed (CBDCA+PEM) and those undergoing carboplatin plus paclitaxel (CBDCA+PTX) chemotherapy.
\end{abstract}

Methods: Pooled data of 240 patients from two prospective observational studies were compared using propensity score matching. Separate multivariate logistic regression analyses were used to identify risk factors for nausea and vomiting following chemotherapy.

Results: Delayed nausea was significantly more common in patients treated with CBDCA+PEM than in those treated with CBDCA+PTX (51.1\% vs. $36.2 \%, P=0.04)$, but the incidence of vomiting did not significantly differ between the two groups ( $23.4 \%$ vs. $14.9 \%, P=0.14)$. The occurrence of CINV peaked on day 4 in the CBDCA+PTX group and on day 5 in the CBDCA+PEM group. Multivariate analysis showed that female sex, younger age, and CBDCA+PEM regimen were independent risk factors for delayed nausea, while female sex was an independent risk factor for delayed vomiting.

Conclusions: The CBDCA + PEM regimen has a higher risk of causing delayed nausea than the CBDCA + PTX regimen, and aggressive antiemetic prophylaxis should be offered to patients treated with CBDCA + PEM.

Keywords: Antiemetics, Chemotherapy-induced nausea and vomiting, Emetogenicity, Lung cancer, Classification, Carboplatin

\footnotetext{
* Correspondence: toshinobu@fukuoka-u.ac.jp

${ }^{1}$ Department of Pharmaceutical and Health Care Management, Faculty of Pharmaceutical Sciences, Fukuoka University, 8-19-1, Nanakuma. Jonan-ku, Fukuoka 814-0180, Japan

Full list of author information is available at the end of the article
}

C C The Author(s). 2021 Open Access This article is licensed under a Creative Commons Attribution 4.0 International License, which permits use, sharing, adaptation, distribution and reproduction in any medium or format, as long as you give appropriate credit to the original author(s) and the source, provide a link to the Creative Commons licence, and indicate if changes were made. The images or other third party material in this article are included in the article's Creative Commons licence, unless indicated otherwise in a credit line to the material. If material is not included in the article's Creative Commons licence and your intended use is not permitted by statutory regulation or exceeds the permitted use, you will need to obtain permission directly from the copyright holder. To view a copy of this licence, visit http://creativecommons.org/licenses/by/4.0/. The Creative Commons Public Domain Dedication waiver (http://creativecommons.org/publicdomain/zero/1.0/) applies to the data made available in this article, unless otherwise stated in a credit line to the data. 


\section{Background}

Chemotherapy-induced nausea and vomiting (CINV) is one of the most dreaded and distressing adverse events in cancer chemotherapy. Antiemetic treatment was markedly improved by the development of antiemetic agents such as 5-hydroxytryptamine-3 receptor antagonists (5-HT3RAs) and neurokinin-1 receptor antagonists (NK1RAs). Further, guidelines for antiemetic therapy are now available including those prepared by the American Society of Clinical Oncology [1], the Multinational Association of Supportive Care in Cancer/European Society of Medical Oncology [2], the National Comprehensive Cancer Network [3], and Japanese Society of Clinical Oncology [4]. The emetogenic classification of antineoplastic agents has also provided a framework for defining antiemetic treatment recommendations in these guidelines. The most widely used classification schema identifies four emetic risk levels (i.e., expected frequency of emesis in the absence of antiemetic prophylaxis): minimal emetic risk, < 10\%; low emetic risk, 10-30\%; moderate emetic risk, 30-90\%; and high emetic risk, > 90\% [5]. Despite these improvements, CINV in high emetic-risk chemotherapies remains insufficiently controlled, particularly in the delayed phase.

In the recently updated guidelines [1-4], CBDCA (AUC > 4) was re-classified from a moderate emetic risk group to a high emetic risk group, and a three-drug combination of a 5-HT3RA, NK1RA, and dexamethasone (DEX) was recommended for antiemetic treatment. However, this change was based on the results obtained from patients who received CBDCA as a part of a moderate emetic risk chemotherapy regimen or from studies with a small sample size [6-12]. Although antineoplastic agents or combination regimens can have the same emetic risk category, each agent or combination regimen may have different emetogenicity. However, accurately defining the emetic risk of each agent or regimen remains challenging, and thus information on the emetogenicity of each agent or chemotherapeutic regimen is currently lacking. Precise information on the emetic risk of each agent or regimen will be helpful for the development of effective and individualized antiemetic treatment.

We previously reported that pemetrexed or gemcitabine has higher emetic risk than taxanes (e.g., paclitaxel or docetaxel) [13]. Therefore, we hypothesized that the incidence and the patterns of CINV differ depending on the type of low emetic risk antineoplastic agent that was combined with CBDCA. In this study, we aimed to investigate the risk factors for CINV in patients with lung cancer receiving carboplatin plus pemetrexed (CBDCA+ PTX) or carboplatin plus paclitaxel (CBDCA+PEM) and determine the difference in the emetic risk between these two regimens.

\section{Methods}

\section{Study design}

We analyzed pooled data of 240 patients from two multicenter, prospective, observational studies. Individual study results were previously published [14, 15]. The patient selection flowchart is shown in Fig. 1. Both studies included patients scheduled to receive moderately emetic chemotherapy in Japan and were approved by their respective institutional review boards [study A, the institutional review board of Fukuoka University Hospital; study B, the institutional review board of National Cancer Center Hospital East]. Written informed consent was obtained from all participating patients before any related study procedure was initiated. All procedures performed in studies involving human participants were in accordance with the ethical standards of the institutional research committee and with the 1964 Helsinki declaration and its later amendments or comparable ethical standards.

\section{Data collection}

Patients enrolled in these two studies were required to be at least 20 years of age, have solid cancer, and be chemotherapy-naïve. The data source included 7-day diaries that started on the day of chemotherapy. CINV data were based on patient self-reports using their diaries. Eligible patients received two antiemetics (palonosetron or first-generation 5-HT3RAs [i.e., ondansetron, and granisetron] and DEX) or three antiemetics (two antiemetics plus aprepitant), all of which were given within $1 \mathrm{~h}$ before their scheduled chemotherapy.

\section{Statistical analysis}

Patient characteristics and the incidence of CINV were summarized using descriptive statistics or contingency tables and were compared using the Student's $t$-test and Chi-square test. Propensity score matching (PSM) was used to balance the characteristics between the CBDCA+PEM group and the CBDCA+PTX group and to reduce bias. Propensity scores to determine matched pairs between the groups were created using five variables (age, sex, drinking habit, history of motion sickness, and antiemetic prophylaxis) that could potentially influence the occurrence of CINV for patients with lung cancer. The propensity scores were then calculated using a logistic regression model. Patients were matched in a 1:1 ratio using a calliper width of 0.2 of the standard deviation from the propensity score logit.

Additionally, independent risk factors for CINV were evaluated using logistic regression analysis with the backward elimination method. A two-sided $P$ value of $<0.05$ was considered significant, except for independent risk factors where the significance level was set at $P<0.1$. 


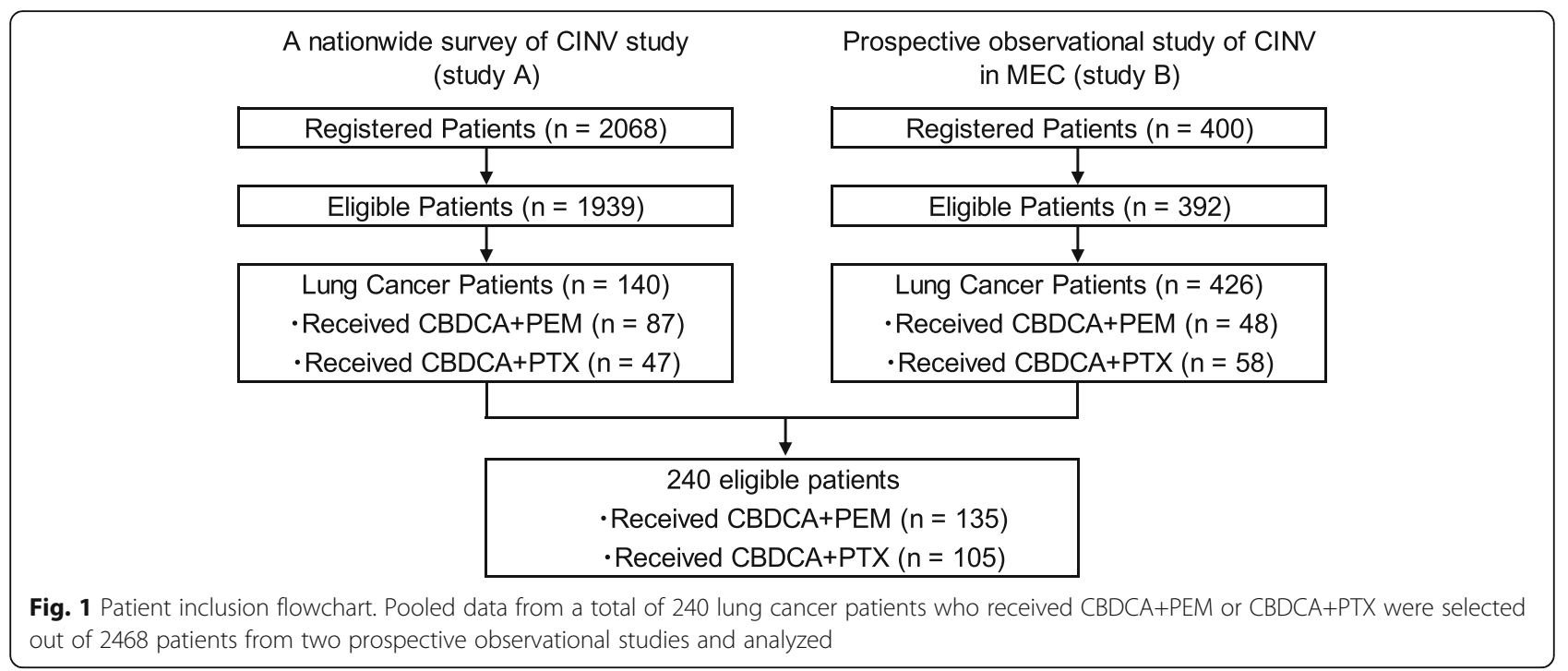

Furthermore, the antiemetic treatment failure curves in each chemotherapeutic regimen group were evaluated using the Kaplan- Meier method and compared between the two groups using the log-rank test. The PSM population was used for all analyses of the occurrence and risk factors for CINV. Sensitivity analysis was conducted to determine whether this conclusion was consistent between the overall cohort and the PSM population. Data from the overall cohort (before PSM matching) and from the PSM population were compared. All statistical analyses were performed using SAS 9.4 (SAS Institute, Cary, NC, USA).

\section{Results}

\section{Patient characteristics}

A total of 240 patients were included in the analysis: 134 (55.8\%) and 106 (44.2\%) patients from studies A and B, respectively. Overall, 135 (87 and 48 in studies A and B, respectively) received CBDCA+PEM, and 105 (47 and 58 in studies $\mathrm{A}$ and $\mathrm{B}$, respectively) received $\mathrm{CBDCA}+\mathrm{PTX}$. Their baseline characteristics including age, motion sickness, drinking habits, and antiemetic prophylaxis are shown in Table 1. There were no significant differences between the two groups after the PSM (Table 1).

\section{Incidence of CINV}

The incidence of CINV is shown in Fig. 2. The incidence of delayed nausea was significantly higher in the matched CBDCA+PEM group than that in the matched CBDCA+PTX group (51.1\% vs. $36.2 \%, P=0.040)$. However, there were no significant differences between the matched CBDCA+PEM group and the matched

Table 1 Patient characteristics

\begin{tabular}{|c|c|c|c|c|c|c|c|c|c|c|c|}
\hline \multirow[t]{4}{*}{ Characteristics } & & \multicolumn{5}{|c|}{ Before propensity score matching } & \multicolumn{5}{|c|}{ After propensity score matching } \\
\hline & & \multirow{2}{*}{\multicolumn{2}{|c|}{$\begin{array}{l}\text { CBDCA+PEM } \\
(n=135)\end{array}$}} & \multirow{2}{*}{\multicolumn{2}{|c|}{$\begin{array}{l}\text { CBDCA+PTX } \\
(n=105)\end{array}$}} & \multirow[t]{3}{*}{$p$-value } & \multirow{2}{*}{\multicolumn{2}{|c|}{$\begin{array}{l}\text { CBDCA+PEM } \\
(n=94)\end{array}$}} & \multirow{2}{*}{\multicolumn{2}{|c|}{$\begin{array}{l}\text { CBDCA+PTX } \\
(n=94)\end{array}$}} & \multirow[t]{3}{*}{$p$-value } \\
\hline & & & & & & & & & & & \\
\hline & & $n$ & $(\%)$ & n & $(\%)$ & & n & $(\%)$ & n & (\%) & \\
\hline \multirow[t]{2}{*}{ Sex } & Male & 84 & $(62.2)$ & 89 & $(84.8)$ & $<0.001$ & 78 & $(83.0)$ & 78 & $(83.0)$ & 1.000 \\
\hline & Female & 51 & $(37.8)$ & 16 & $(15.2)$ & & 16 & $(17.0)$ & 16 & $(17.0)$ & \\
\hline \multirow[t]{2}{*}{ Age, years } & $<65$ & 56 & $(41.5)$ & 46 & $(43.8)$ & 0.793 & 37 & (39.4) & 43 & $(45.7)$ & 0.461 \\
\hline & $\geq 65$ & 79 & $(58.5)$ & 59 & $(56.2)$ & & 57 & $(60.6)$ & 51 & $(54.3)$ & \\
\hline \multirow[t]{2}{*}{ Motion sickness } & No & 122 & $(90.4)$ & 99 & $(94.3)$ & 0.338 & 85 & $(90.4)$ & 89 & $(94.7)$ & 0.406 \\
\hline & Yes & 13 & $(9.6)$ & 6 & $(5.7)$ & & 9 & $(9.6)$ & 5 & $(5.3)$ & \\
\hline \multirow[t]{2}{*}{ Drinking habit } & No & 78 & $(57.8)$ & 52 & $(49.5)$ & 0.240 & 45 & $(47.9)$ & 45 & $(47.9)$ & 1.000 \\
\hline & Yes & 57 & $(42.2)$ & 53 & $(50.5)$ & & 49 & $(52.1)$ & 49 & $(52.1)$ & \\
\hline \multirow[t]{2}{*}{ Number of antiemetics } & 2 & 95 & (70.4) & 91 & $(86.7)$ & 0.003 & 80 & (85.1) & 80 & (85.1) & 1.000 \\
\hline & 3 & 40 & (29.6) & 14 & (13.3) & & 14 & (14.9) & 14 & (14.9) & \\
\hline
\end{tabular}




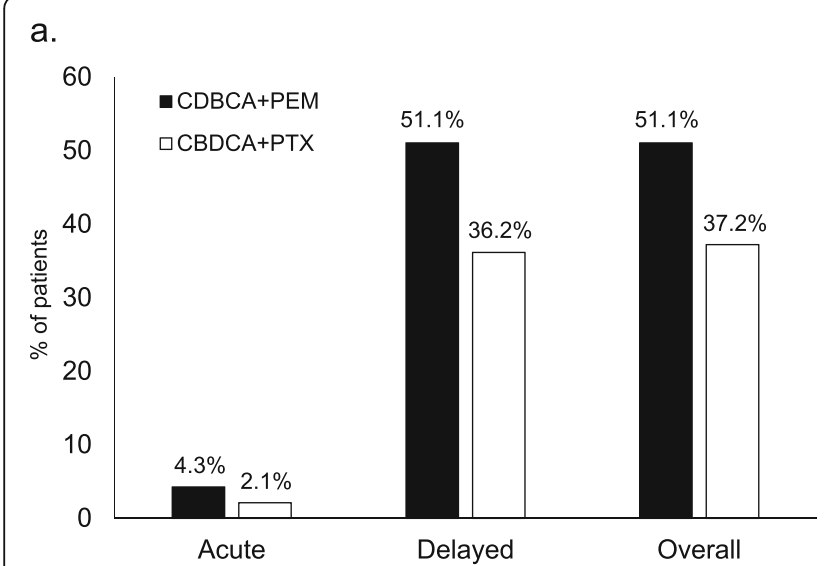

b.

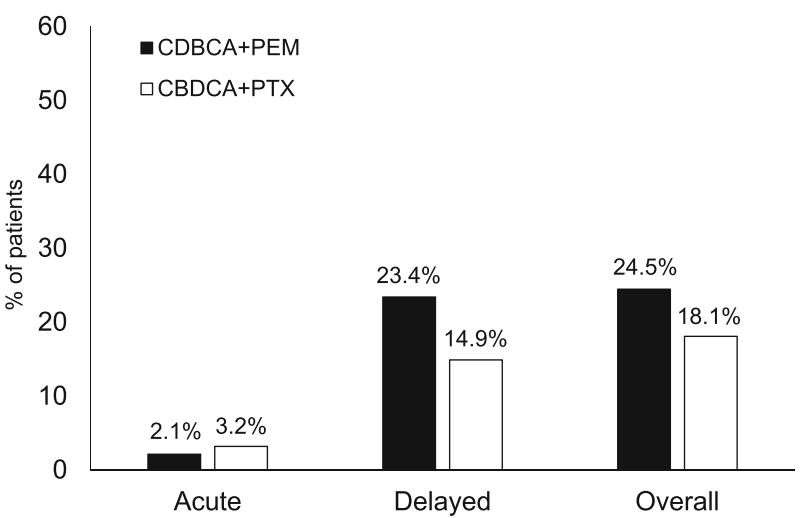

Fig. 2 Incidence of nausea and vomiting. The incidence of nausea (a) and vomiting (b) in the acute phase, delayed phase, and overall treatment period. Black bars denote the CBDCA+PEM group, while white bars indicate the CBDCA+PTX group. The incidence of delayed nausea was significantly higher in the CBDCA+PEM group than that in the CBDCA+PTX group
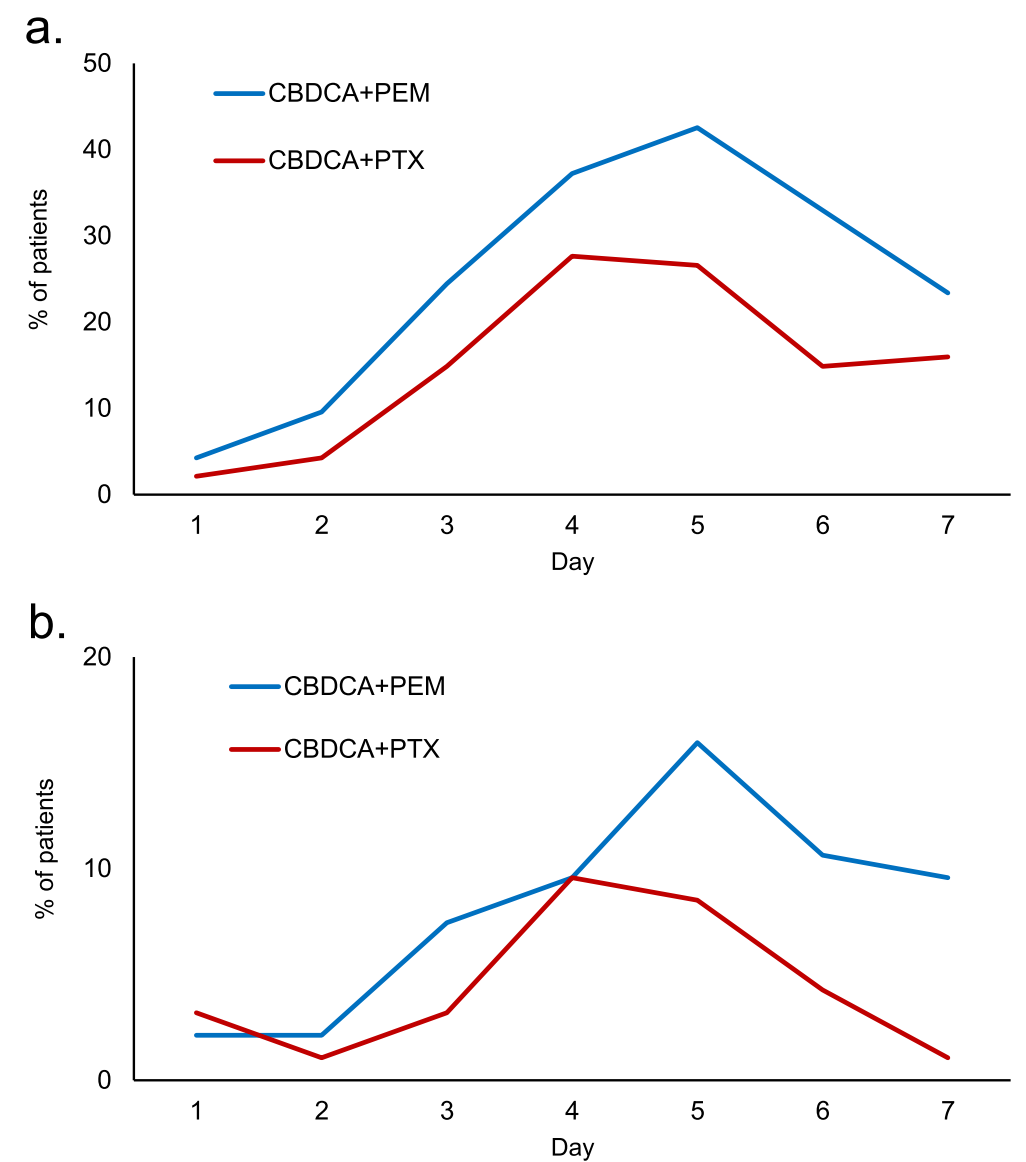

Fig. 3 Patterns of CINV occurrence. Occurrence pattern of nausea (a) and vomiting (b) from day 1 to day 7 . The occurrence of nausea and vomiting peaked on days 5 and 4 for the CBDCA+PEM and the CBDCA+PTX groups, respectively. CINV tended to be delayed in the CBDCA+PEM group 
CBDCA+PTX group with respect to the incidence of overall, acute, or delayed vomiting.

\section{Pattern of CINV incidence}

The incidence of CINV occurring from day 1 to day 7 after chemotherapy is shown in Fig. 3. In both groups, the incidence of nausea on days 1 and 2 was low and gradually increased, peaking on days 4 and 5 , followed by a gradual decline. The incidence of vomiting in the CBDCA+PTX group showed a similar pattern, whereas the incidence of vomiting in the CBDCA+PEM group remained high after day 5. Kaplan-Meier curve of time to antiemetic treatment failure (TTF) in nausea is shown in Fig. 4. Kaplan-Meier curves of time to nausea event according to each chemotherapeutic regimen showed that there was no statistically significant difference between the two groups.

\section{Risk factors for CINV}

The results of univariate and multivariate logistic regression analyses of risk factors for delayed CINV are shown in Fig. 5. Sex, age, motion sickness, drinking habits, antiemetic prophylaxis, and chemotherapeutic regimen were analyzed. Female sex, age $<65$ years, drinking habit, double antiemetic regimen, and CBDCA+PEM were identified as risk factors for delayed nausea. Meanwhile, female sex and two-antiemetic regimen were identified as risk factors for delayed vomiting.

\section{Sensitivity analysis}

The results of the sensitivity analysis for the patterns in the incidence of CINV and TTF in nausea were consistent across the overall and PSM population (Figs. 3 and 4, Supplementary figures 1 and 2).

\section{Discussion}

The present study demonstrated a higher incidence of CINV in patients who received CBDCA+PEM than in those who received $\mathrm{CBDCA}+\mathrm{PTX}$ therapy. Further, the $\mathrm{CBDCA}+\mathrm{PEM}$ regimen was an independent risk factor for nausea in the delayed phase. While acute CINV was well controlled in both groups, the incidence of delayed nausea was significantly higher in the CBDCA+PEM group than that in the CBDCA+PTX group (51.1\% vs. $36.2 \%, P=0.040)$. Although the incidence of delayed vomiting was not significantly different between the two groups, the incidence of vomiting in the CBDCA+PEM group tended to be high $(23.4 \%$ vs. $14.9 \%, P=0.138)$.

Knowing the CINV incidence pattern is important for determining the optimal antiemetic treatment. In patients who received anthracycline + cyclophosphamide regimens with antiemetic prophylaxis, nausea peaked on day 2 [14]. Meanwhile, in this study, nausea and vomiting peaked on day 5 in patients who received CBDCA regimens with antiemetic prophylaxis. This incidence pattern was similar to that observed for cisplatin [14]. Although there were no significant differences in the time to nausea event $(p=0.076)$, the incidence rate of CINV, patterns of CINV incidence, and TTF suggest that the control of delayed nausea in patients receiving CBDCA+PEM needs to be improved.

Moreover, it is important to identify patients with a high risk of CINV so that appropriate measures to preserve the quality of life and ensure continuity of

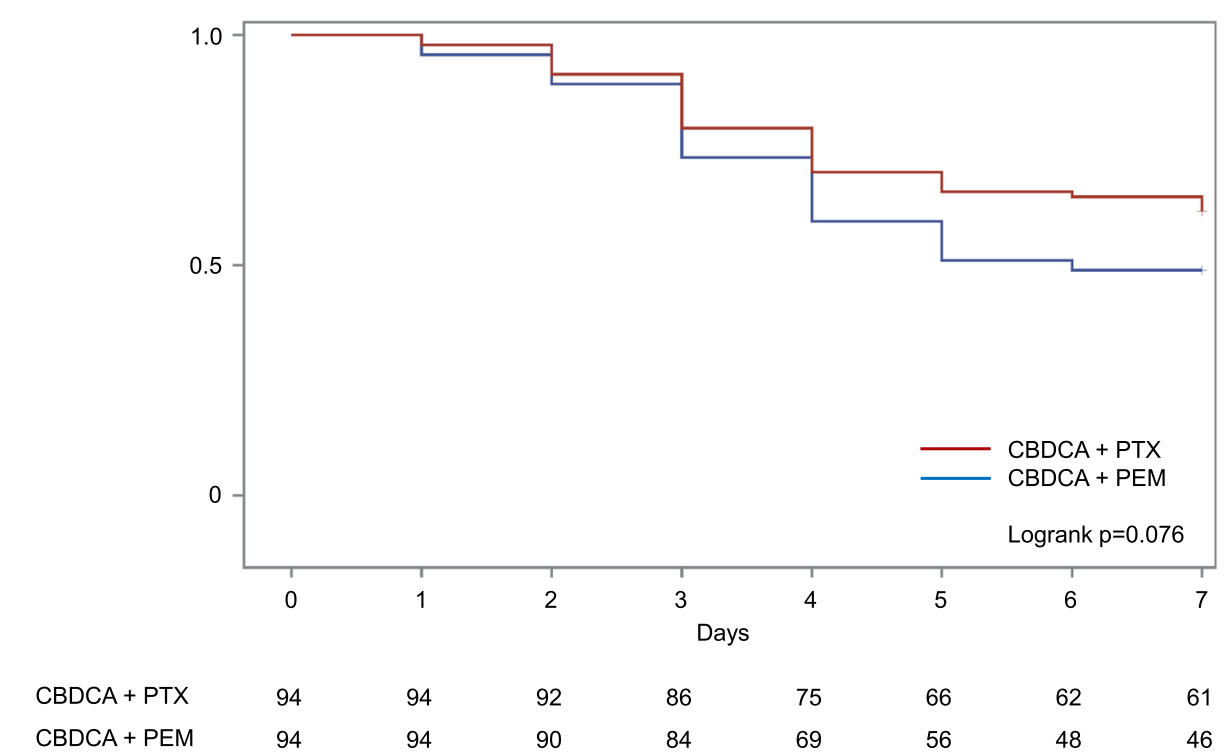

Fig. 4 Time to antiemetic treatment failure in nausea. Kaplan-Meier curves of time to nausea event according to each chemotherapeutic regimen showed that there was no statistically significant difference 
a.

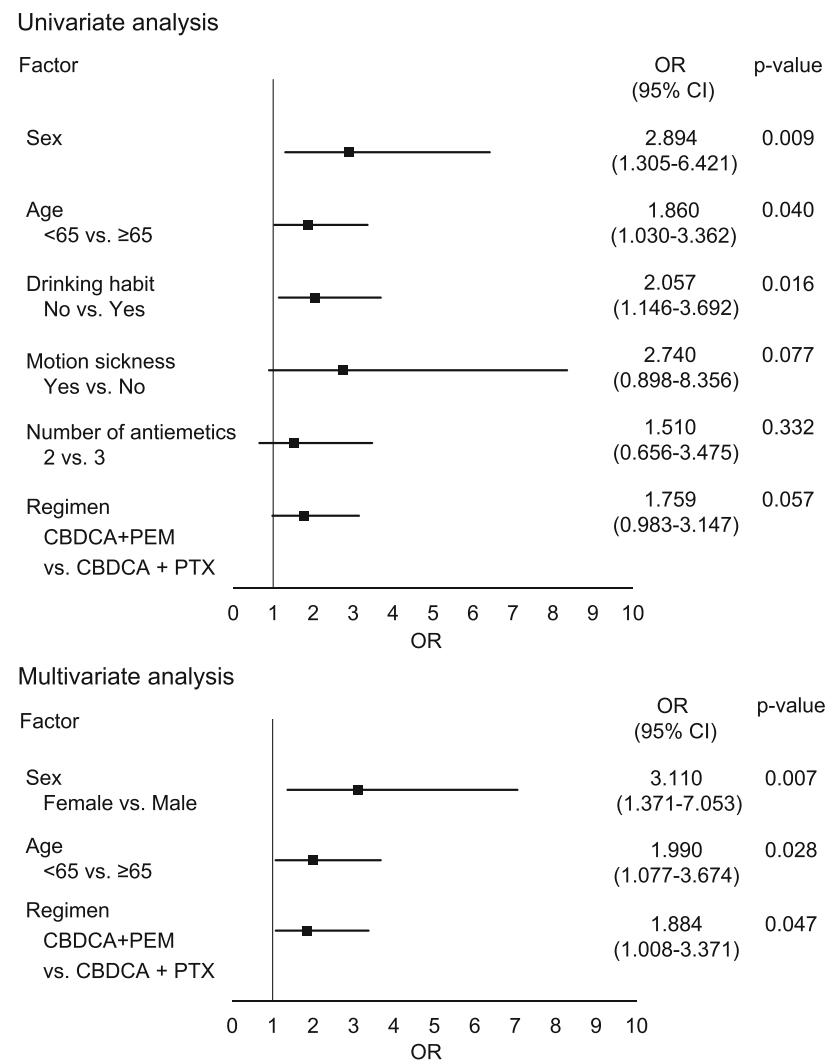

b.

Univariate analysis

Factor

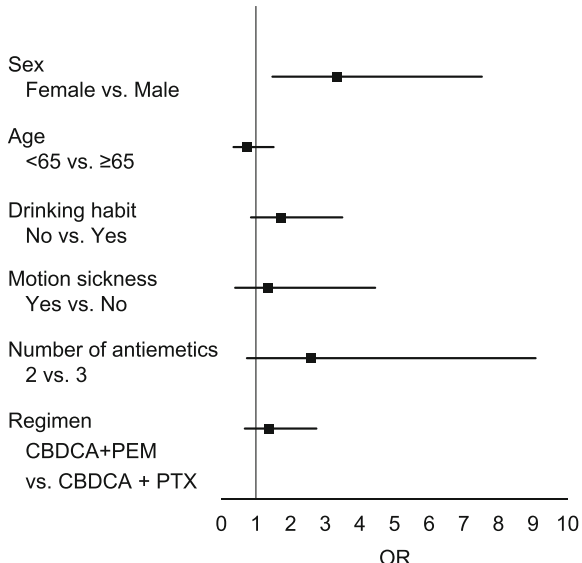

OR p-value

$\begin{array}{ll}3.335 & 0.004\end{array}$

(1.479-7.522)

$0.731 \quad 0.397$

(0.354-1.508)

$\begin{array}{ll}1.732 & 0.125\end{array}$

(0.859-3.493)

$1.337 \quad 0.636$

$(0.402-4.441)$

$2.595 \quad 0.135$

(0.742-9.074)

$1.368 \quad 0.378$

(0.682-2.745) 0.378

Multivariate analysis

Factor

Age

$<65$ vs. $\geq 65$

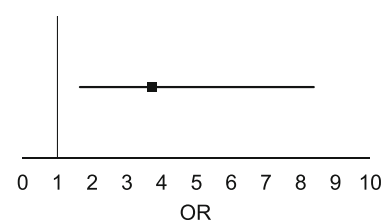

$\begin{array}{cc}\underset{\mathrm{OR}}{95 \% \mathrm{Cl})} & p \text {-value } \\ 3.716 & 0.002\end{array}$

(1.649-8.373)

Fig. 5 Risk factors for delayed nausea and vomiting. Univariate and multivariate analyses were conducted to identify the risk factors for delayed nausea (a) and vomiting (b). OR; odds ratio, Cl; confidence interval 
chemotherapy can be implemented. In this study, logistic regression analysis identified younger age, female sex, and $\mathrm{CBDCA}+\mathrm{PEM}$ as independent risk factors associated with delayed nausea, and female sex as associated with delayed vomiting. Female sex and young age are wellknown risk factors for CINV [16-19]. It is worth noting that the CBDCA+PEM regimen has been identified in this study as an independent risk factor for delayed nausea, along with these well-known patient-related risk factors.

We previously reported that the incidence of CINV was significantly higher in patients receiving pemetrexed or gemcitabine (GEM) than that in patients receiving taxane [13], and consistent results were obtained in this study. The CBDCA+PTX regimen requires premedication of $20 \mathrm{mg}$ DEX, H1-blocker, and H2-blocker for allergy prevention on day 1 . Although these agents may enhance the antiemetic effect, they have limited efficacy, as indicated by the incidence and pattern of CINV observed in this study. Therefore, the optimal antiemetic therapy still needs to be determined carefully for each CBDCA-based regimen, even for those in the same emetic risk category.

CINV in patients receiving CBDCA+PTX can be controlled relatively well by two antiemetics $[8,15]$. Ito et al. [8] reported that the CBDCA+PEM regimen had relatively high emetic potential, and triple antiemetic therapy with a 5-HT3 receptor antagonist, DEX, and aprepitant may be an effective prophylactic treatment in patients receiving the CBDCA+PEM regimen. However, they evaluated CINV according to complete response (no vomiting and no rescue medication), and the incidence of nausea was unclear. In our study, the incidence of nausea was higher in the CBDCA+PEM group than that in the CBDCA+PTX group at the delayed phase, highlighting the need for improving the control of nausea in the delayed phase. Meanwhile, GEM may also have a higher risk of emesis among low emetic risk chemotherapies [13]. Data from previous clinical trials suggest that CBDCA+GEM may have a higher risk of CINV than CBDCA+PTX $[20,21]$. However, we were unable to analyze this case because of the small number of patients who received CBDCA+GEM. In addition, there are no reports directly comparing the incidence of nausea and vomiting between CBDCA+GEM and CBDCA+ PTX. It is also unclear whether there is a clinically meaningful difference in terms of emetic risk between $\mathrm{CBDCA}+\mathrm{PEM}$ and $\mathrm{CBDCA}+\mathrm{GEM}$.

The efficacy and safety of $10 \mathrm{mg}$ olanzapine and standard triplet antiemetic therapy were shown in a randomized, double-blind phase III study in patients who received highly emetogenic chemotherapy including anthracycline/cyclophosphamide and cisplatin [22]. Hashimoto et al. [23] reported that $5 \mathrm{mg}$ of olanzapine combined with aprepitant, palonosetron, and dexamethasone provided a significant improvement in delayed CINV. Further, there were no significant differences in the incidence of daytime sleepiness between the olanzapine group and the placebo group among the patients receiving cisplatin-based chemotherapy. Tanaka et al. [24] reported that adding olanzapine to aprepitant, 5-HT3RA, and DEX improved CINV control in patients receiving CBDCA-based chemotherapy. Adding olanzapine to standard triplet antiemetic therapy is considered a promising option to improve control of delayed nausea in patients receiving CBDCA+PEM.

This study has some limitations. First, it was not a blinded, randomized control trial. Second, some risk factors of CINV such as smoking habits and morning sickness could not be analyzed. Finally, the results of this study were obtained from a Japanese population, and while the results may be applicable to other Asian populations, further research is needed to verify the generalizability of these results to other races. Despite these limitations, the findings described the emetogenicity of and risk factors for CBDCA-based regimens in routine clinical practice, rather than in a controlled trial, and therefore might reflect the real-world conditions. Further, the use of data with a sufficient number of events from two prospective observational studies and PSM enabled high accuracy and robustness of the results.

\section{Conclusion}

The CBDCA + PEM regimen had a higher risk of causing nausea than the CBDCA + PTX regimen. The optimal antiemetic therapy for each regimen in CBDCAbased chemotherapy should be carefully chosen because delayed CINV, especially nausea, is still insufficiently controlled in some patients who receive the CDBCA+ PEM regimen. Patients who are female, aged $<65$ years, and receiving CBDCA+PEM have a high risk of CINV, and thus additional antiemetics for delayed CINV (e.g., olanzapine) should be considered for these patients.

\section{Supplementary Information}

The online version contains supplementary material available at https://doi. org/10.1186/s12885-021-07802-y.

Additional file 1: Supplementary figure 1. Patterns of CINV occurrence in overall population. Occurrence pattern of nausea (a) and vomiting (b) from day 1 to day 7 . The patterns in the incidence of CINV was consistent across the overall and PSM population.

Additional file 2: Supplementary figure 2. TTF of nausea in overall population. Kaplan-Meier curves of time to nausea event according to each chemotherapeutic regimen showed that there was statistically significant difference between the two groups.

\section{Abbreviations}

CINV: Chemotherapy-induced nausea and vomiting; CBDCA+PEM: Cancer patients undergoing carboplatin plus pemetrexed; CBDCA+PTX: Paclitaxel; 5- 
HT3RAs: 5-hydroxytryptamine-3 receptor antagonists; NK1RAs: Neurokinin-1 receptor antagonists; DEX: Dexamethasone

\section{Acknowledgments}

We wish to thank Dr. Kazuo Tamura for his support as the principal investigator of Study A, and Dr. Koichi Goto and Ms. Reiko Matsui for their support as the principal investigators of Study B. We would also like to thank all the participants of the aforementioned studies and their families.

\section{Authors' contributions}

T.H. conceived the study. T.H., K.M. and M.S. conducted the claim data analysis. M.S. performed the statistical analyses. K.M. and H.I. provided technical support. T.H., M.S., K.M., H.I., K.K., T.N., and T.E. contributed to the interpretation of data and assisted in the preparation of the manuscript. T.H. and M.S. drafted the initial manuscript. T.H., M.S., K.M., H.I., K.K., T.N., and T.E. conducted the critical revision of the manuscript. All authors reviewed the manuscript.

\section{Funding}

This research did not receive any specific grant from funding agencies in the public, commercial, or not-for-profit sectors.

\section{Availability of data and materials}

Availability of data and material: The data that support the findings of this study are available from both study groups of study A and study B but restrictions apply to the availability of these data, which were used under license for the current study, and therefore, the data are not publicly available. However, data are available from the authors upon reasonable request and with permission of both study groups of study $A$ and study $B$.

\section{Ethics approval and consent to participate}

This study was approved by the institutional review board of Fukuoka University (H20-08-004). The datasets used for this study were provided by the principal investigators of studies A [14] and B [15].

\section{Consent for publication}

NA.

\section{Competing interests}

The authors declare no competing interests.

\section{Author details}

'Department of Pharmaceutical and Health Care Management, Faculty of Pharmaceutical Sciences, Fukuoka University, 8-19-1, Nanakuma. Jonan-ku, Fukuoka 814-0180, Japan. ${ }^{2}$ Department of Biostatistics, Yamaguchi University Graduate School of Medicine, 1-1-1, Minamiogushi, Ube, Yamaguchi 755-8505, Japan. ${ }^{3}$ Department of Pharmacy, Fukuoka University Chikushi Hospital, 1-1-1, Zokumyoin, Chikushino, Fukuoka 818-0067, Japan. ${ }^{4}$ Department of Pharmacy, Gifu University Hospital, 1-1, Yanagido, Gifu City 501-1194, Japan. ${ }^{5}$ Department of Pharmacy, Kochi Medical School Hospital, 185-1 Kohasu, Oko town, Nankoku City, Kochi 783-8505, Japan.

\section{Received: 28 May 2020 Accepted: 11 January 2021}

Published online: 15 January 2021

\section{References}

1. Hesketh PJ, Kris MG, Basch E, Bohlke K, Barbour SY, Clark-Snow RA, et al. Antiemetics: American Society of Clinical Oncology clinical practice guideline update. J Clin Oncol. 2017;35:3240-61. https://doi.org/10.1200/jco. 2017.74.4789.

2. Roila F, Warr D, Hesketh PJ, Gralla R, Herrstedt J, Jordan K, et al. B. 2016 updated MASCC/ESMO consensus recommendations: prevention of nausea and vomiting following moderately emetogenic chemotherapy. Support Care Cancer. 2017;25:289-94. https://doi.org/10.1007/s00520-016-3365-1.

3. NCCN clinical practice guidelines in oncology (2019) Antiemetics. Version 1, 2019. https://www.nccn.org/professionals/physician_gls/pdf/antiemesis.pdf. Accessed 30 July 2019.

4. JSCO guidelines for antiemetics in oncology 2015. Version 2.2, 2018. http:// www.jsco-pg.jp/item/29/index.html. Accessed 30 July 2019.

5. Jordan K, Chan A, Gralla RJ, Jahn F, Rapoport B, Warr D, Hesketh PJ. 2016 updated MASCC/ESMO consensus recommendations: emetic risk classification and evaluation of the emetogenicity of antineoplastic agents. Support Care Cancer. 2017;25:271-5. https://doi.org/10.1007/ s00520-016-3332-x.

6. Hesketh PJ, Schnadig ID, Schwartzberg LS, Modiano MR, Jordan K, Arora S, et al. Efficacy of the neurokinin-1 receptor antagonist rolapitant in preventing nausea and vomiting in patients receiving carboplatin-based chemotherapy. Cancer. 2016;122:2418-25. https://doi.org/10.1002/cncr.30054.

7. Weinstein C, Jordan K, Green SA, Camacho E, Khanani S, BeckfordBrathwaite $E$, et al. Evaluation of factors contributing to the response to fosaprepitant in a heterogeneous, moderately emetogenic chemotherapy population: an exploratory analysis of a randomized phase III trial. Support Care Cancer. 2018;26:3773-80. https://doi.org/10.1007/s00520-018-4242-X.

8. Ito Y, Karayama M, Inui N, Kuroishi S, Nakano H, Nakamura Y, et al. Aprepitant in patients with advanced non-small-cell lung cancer receiving carboplatin-based chemotherapy. Lung Cancer. 2014;84:259-64. https://doi. org/10.1016/j.lungcan.2014.03.017.

9. Kusagaya H, Inui N, Karayama M, Fujisawa T, Enomoto N, Kuroishi S, et al. Evaluation of palonosetron and dexamethasone with or without aprepitant to prevent carboplatin-induced nausea and vomiting in patients with advanced non-small-cell lung cancer. Lung Cancer. 2015;90:410-6. https:// doi.org/10.1016/j.lungcan.2015.11.009.

10. Maehara M, Ueda T, Miyahara D, Takahashi Y, Miyata K, Nam SO, et al. Clinical efficacy of aprepitant in patients with gynecological cancer after chemotherapy using paclitaxel and carboplatin. Anticancer Res. 2015;35: 4527-34.

11. Tanioka M, Kitao A, Matsumoto K, Shibata N, Yamaguchi S, Fujiwara K, et al. A randomised, placebo-controlled, double-blind study of aprepitant in nondrinking women younger than 70 years receiving moderately emetogenic chemotherapy. Br J Cancer. 2013;109:859-65. https://doi.org/10. 1038/bjc.2013.400

12. Yahata H, Kobayashi H, Sonoda K, Shimokawa M, Ohgami T, Saito T, et al. Efficacy of aprepitant for the prevention of chemotherapy-induced nausea and vomiting with a moderately emetogenic chemotherapy regimen: a multicenter, placebo-controlled, double-blind, randomized study in patients with gynecologic cancer receiving paclitaxel and carboplatin. Int I Clin Oncol. 21:491-7. https://doi.org/10.1007/s10147-015-0928-y.

13. Hayashi T, Shimokawa M, Miyoshi T, Toriyama Y, Yokota C, Taniguchi J, et al. A prospective, observational, multicenter study on risk factors and prophylaxis for low emetic risk chemotherapy-induced nausea and vomiting. Support Care Cancer. 2017;25:2707-14. https://doi.org/10.1007/ s00520-017-3679-7.

14. Tamura K, Aiba K, Saeki T, et al. Testing the effectiveness of antiemetic guidelines: results of a prospective registry by the CINV study Group of Japan. Int J Clin Oncol. 2015;20:855-65. https://doi.org/10.1007/s10147015-0786-7.

15. Matsui R, Suzuki K, Takiguchi T, Nishio M, Koike T, Hayashi T, et al. 5Hydroxytryptamine-3 receptor antagonist and dexamethasone as prophylaxis for chemotherapy-induced nausea and vomiting during moderately emetic chemotherapy for solid tumors: a multicenter, prospective, observational study. BMC Pharmacol Toxicol. 2020;21:72. https://doi.org/10.1186/s40360-020-00445-y.

16. Hesketh PJ, Aapro M, Street JC. Carides AD (2010) evaluation of risk factors predictive of nausea and vomiting with current standard-of-care antiemetic treatment: analysis of two phase III trials of aprepitant in patients receiving cisplatin-based chemotherapy. Support Care Cancer. 2010;18:1171-7. https://doi.org/10.1007/s00520-009-0737-9.

17. Warr DG, Street JC, Carides AD. Evaluation of risk factors predictive of nausea and vomiting with current standard-of-care antiemetic treatment: analysis of phase 3 trial of aprepitant in patients receiving adriamycincyclophosphamide-based chemotherapy. Support Care Cancer. 2011;19: 807-13. https://doi.org/10.1007/s00520-010-0899-5.

18. Hilarius DL, Kloeg PH, van der Wall E, van den Heuvel JJ, Gundy CM, Aaronson NK. Chemotherapy-induced nausea and vomiting in daily clinical practice: a community hospital-based study. Support Care Cancer. 2012;20: 107-17. https://doi.org/10.1007/s00520-010-1073-9.

19. Aapro M, Molassiotis A, Dicato $M$, et al. The effect of guideline-consistent antiemetic therapy on chemotherapy-induced nausea and vomiting (CINV): the Pan European Emesis registry (PEER). Ann Oncol. 2012;23:1986-92. https://doi.org/10.1093/annonc/mds021.

20. Ohe $Y$, Ohashi $Y$, Kubota K, et al. Randomized phase III study of cisplatin plus irinotecan versus carboplatin plus paclitaxel, cisplatin plus gemcitabine, 
and cisplatin plus vinorelbine for advanced non-small-cell lung cancer: fourarm cooperative study in Japan. Ann Oncol. 2007;18:317-23. https://doi.org/ 10.1093/annonc/mdl377.

21. Sakurai R, Tomizawa Y, Yoshii A, et al. A phase II study of biweekly gemcitabine and carboplatin in completely resected stage IB-IIIA non-small cell lung cancer. Cancer Chemother Pharmacol. 2018;81:103-9. https://doi. org/10.1007/s00280-017-3439-x.

22. Navari RM, Qin R, Ruddy K, et al. Olanzapine for the prevention of chemotherapy-induced nausea and vomiting. N Engl J Med. 2016;375:13442. https://doi.org/10.1056/NEJMoa1515725.

23. Hashimoto $\mathrm{H}$, Abe M, Tokuyama O, et al. Olanzapine $5 \mathrm{mg}$ plus standard antiemetic therapy for the prevention of chemotherapy-induced nausea and vomiting (J-FORCE): a multicentre, randomised, double-blind, placebocontrolled, phase 3 trial. Lancet Oncol. 2019;21:242-9. https://doi.org/10. 1016/S1470-2045(19)30678-3

24. Tanaka K, Inui N, Karayama M, et al. Olanzapine-containing antiemetic therapy for the prevention of carboplatin-induced nausea and vomiting. Cancer Chemother Pharmacol. 2019;84:147-53. https://doi.org/10.1007/ s00280-019-03868-5.

\section{Publisher's Note}

Springer Nature remains neutral with regard to jurisdictional claims in published maps and institutional affiliations.

Ready to submit your research? Choose BMC and benefit from:

- fast, convenient online submission

- thorough peer review by experienced researchers in your field

- rapid publication on acceptance

- support for research data, including large and complex data types

- gold Open Access which fosters wider collaboration and increased citations

- maximum visibility for your research: over $100 \mathrm{M}$ website views per year

At $\mathrm{BMC}$, research is always in progress.

Learn more biomedcentral.com/submissions 